\title{
Doing the right thing or doing things right: what is better for a successful manufacturing reshoring?
}

\author{
Albachiara Boffelli $^{1}$ (D) $\cdot$ Luciano Fratocchi $^{2}$ (D) Matteo Kalchschmidt ${ }^{1}$ (D) Susana Cristina Lima da Costa e Silva ${ }^{3}$
}

Received: 22 September 2020 / Revised: 8 February 2021 / Accepted: 12 February 2021 / Published online: 3 March 2021

(c) The Author(s) 2021

\begin{abstract}
The article concerns the revision of earlier decisions to offshore production activities (so called "relocation of second degree"); more specifically it is focused on the "reshoring" (also referred as "relocation to the home country", "backreshoring" or "back-shoring"). The research aims are to investigate what types of mistakes occur along the decision-making and implementation process and how they affect the outcome, in terms of success or failure, of a relocation strategy. A multiple case study involving four companies in the fashion industry from Portugal and Italy was conducted. The cross-case analysis allowed to differentiate decision-making mistakes from implementation ones and to assess differences and similarities among the cases in terms of content of the relocation, drivers and outcomes. The research contributes to previous literature on reshoring by bringing evidence of different types of mistakes to be considered, thus requiring further conceptualization of the reshoring process. Managers and entrepreneurs should consider the importance of doing the things right also during the implementation, too often underestimated. The present article is the first one in the reshoring literature bringing evidence of cases of failure in the relocation decisions and discriminating among different kinds of mistakes.
\end{abstract}

Keywords Reshoring $\cdot$ Relocations · Offshoring $\cdot$ Italy $\cdot$ Portugal $\cdot$ Manufacturing

\section{Introduction}

After decades of implementing manufacturing offshoring strategies, in the last few years, companies have been critically evaluating their earlier location decisions. Due to a variety of motivations (Fratocchi et al. 2016; Srai and Ané 2016; Barbieri et al. 2018), companies are modifying these decisions, thus relocating activities either to their home

Albachiara Boffelli

albachiara.boffelli@unibg.it

Luciano Fratocchi

luciano.fratocchi@univaq.it

Matteo Kalchschmidt

matteo.kalchschmidt@unibg.it

Susana Cristina Lima da Costa e Silva

ssilva@porto.ucp.pt

1 Department of Management, Information and Production Engineering, University of Bergamo, Bergamo, Italy

2 Department of Industrial and Information Engineering and Economics, University of L'Aquila, L'Aquila, Italy

3 Católica Porto Business School, R. de Diogo Botelho 1327, 4169-005 Porto, Portugal country (Relocation to the Home Country, RHC) or to a third country (Relocation to a Third Country, RTC), different from the previous one (Barbieri et al. 2019). Moving back to the home country is not an easy journey. In fact, depending on the specific choices made by the firm over the previous offshoring period (Johansson and Olhager 2018), many things might have changed in the home country over time and the company's readiness might not be appropriate to undertake such a journey (Nujen and Halse 2017; Nujen et al. 2018b, a). To add difficulty, even if researchers have dug into the reasons that drive a company to relocate to the home country, little is known about how companies take such decision and the difficulty they face along with its implementation (Barbieri et al. 2018; Boffelli and Johansson 2020; Boffelli et al. 2020).

Reshoring (alternatively called in literature as "backreshoring" or "back-shoring") has been defined as "a voluntary corporate strategy regarding the home-country partial or total relocation of (in-sourced or out-sourced) production to serve local, regional, or global demands" (Fratocchi et al. 2014; Barbieri et al. 2019). This recent phenomenon has been increasingly attracting scholars (for detailed literature reviews we refer to Stentoft et al. 
2016; Wiesmann et al. 2017; Barbieri et al. 2018). Many scholars recognize a major differentiation between reshoring decisions assumed as a result of a "strategic shift" (Baraldi et al. 2018; Di Mauro et al. 2018), triggered by changes either in the external or internal environment (MartínezMora and Merino 2014; Fratocchi et al. 2016), and the ones made as a reaction to a "managerial mistake" (Kinkel and Maloca 2009; Ellram et al. 2013; Kinkel 2014). However, while several works have provided cases of decisions due to changes in the overall strategy, no study has yet considered cases of failure of previous relocation decisions. This is due to the difficulty in getting access to information related to unsuccessful decisions since companies are often not much willing to share their bad experiences. Nevertheless, the analysis of the unsuccessful cases, as well as their comparison with successful ones, can be extremely helpful to shed new light on the reshoring phenomenon and to develop useful managerial implications (Silva and Silva 2012).

Starting from these premises, this paper aims to explore the kind of mistakes that companies can do when addressing a relocation decision. Specifically, we aim to i) understand what types of mistakes, committed by the people involved in the reshoring process (independently of their role within the company), can occur along with the relocation processes - i.e., both offshoring and reshoring - and ii) whether the mistakes occurred in the company's history of relocation decisions may affect the outcome, in terms of failure or success, of reshoring. In alignment with these objectives, this research adopts a multiple-case study approach, involving four companies belonging to the fashion industry (and particularly footwear and clothing), a competitive environment where outsourcing and offshoring strategies have been implemented for a long time (Camuffo et al. 2006). More specifically, the offshoring and reshoring strategies implemented by a Portuguese and three Italian firms have been investigated. To gain an overall picture over the four cases, the framework proposed by Boffelli and Johansson (2020) has been adopted. This framework conceptualizes both offshoring and reshoring processes as made of three building blocks: decision-making, implementation, and outcome. Based on the collected data, we argue that the success of a reshoring decision depends more on whether it was correctly implemented rather than why it was taken (i.e., mistake vs. strategic shift in response to internal or external changes).

The remainder of this paper is structured as follows: section two contains the literature review about reshoring, with a particular focus on decision-making and implementation, and mistakes connected to relocations. In section three, the adopted multiple-case study research methodology is explained, while section four reports the main results through the within and the cross-case analyses of the four case studies. Then, the results are discussed against the previous literature, to let the main theoretical contributions emerge. The latter are discussed, together with managerial implications, limitations and future research directions, in the concluding section.

\section{Literature review}

\subsection{Reshoring drivers and process}

The definition of reshoring reflects a feature of voluntariness of the decision and its strategic relevance, given its potential long-term impact on profitability and competitive position (Gylling et al. 2015). Despite the voluntariness, reshoring decisions are complex and many variables need to be considered, as demonstrated by the huge amount of influencing drivers identified in previous literature (Fratocchi et al. 2016; Srai and Ané 2016; Stentoft et al. 2016; Wiesmann et al. 2017; Barbieri et al. 2018). Employing an extensive literature review, Barbieri et al. (2018) identify 66 different drivers, proving the great heterogeneity of the reasons behind reshoring decisions. As the first step in their categorization effort, the authors separate drivers according to the twofold conceptualization of reshoring as correction of a managerial mistake or as a strategic decision, further divided into internal and external environmental changes. Managerial mistake drivers include, for example, miscalculations of actual costs, lack of knowledge on the host country, lack of systematic location planning and bounded rationality. Instead, strategic decision drivers include factors connected both to the external and to the internal environment and related to specific categories, as reported in Fig. 1.

The assessment of potential drivers, namely the "why" question, represents the first fundamental step in the reshoring process made of decision-making and implementation (Boffelli et al. 2020), namely the "how" question, which is the most under-researched area in the literature about reshoring (Wiesmann et al. 2017; Barbieri et al. 2018). Among the few contributions in this respect, Joubioux and Vanpoucke (2016) develop a framework to guide location decision-making, highlighting a strong path dependency with the previous offshoring decision. Similarly, Bals et al. (2016) first conceptualize the distinction between decision-making and implementation and Gray et al. (2017) add bounded rational features to the decision-making process. Finally, Boffelli and Johansson (2020) provide a comprehensive framework reconciling existing frameworks. Based on these contributions, three major building blocks were considered for the processes both of offshoring and 
Fig. 1 Drivers for reshoring (adapted from Barbieri et al. 2018)

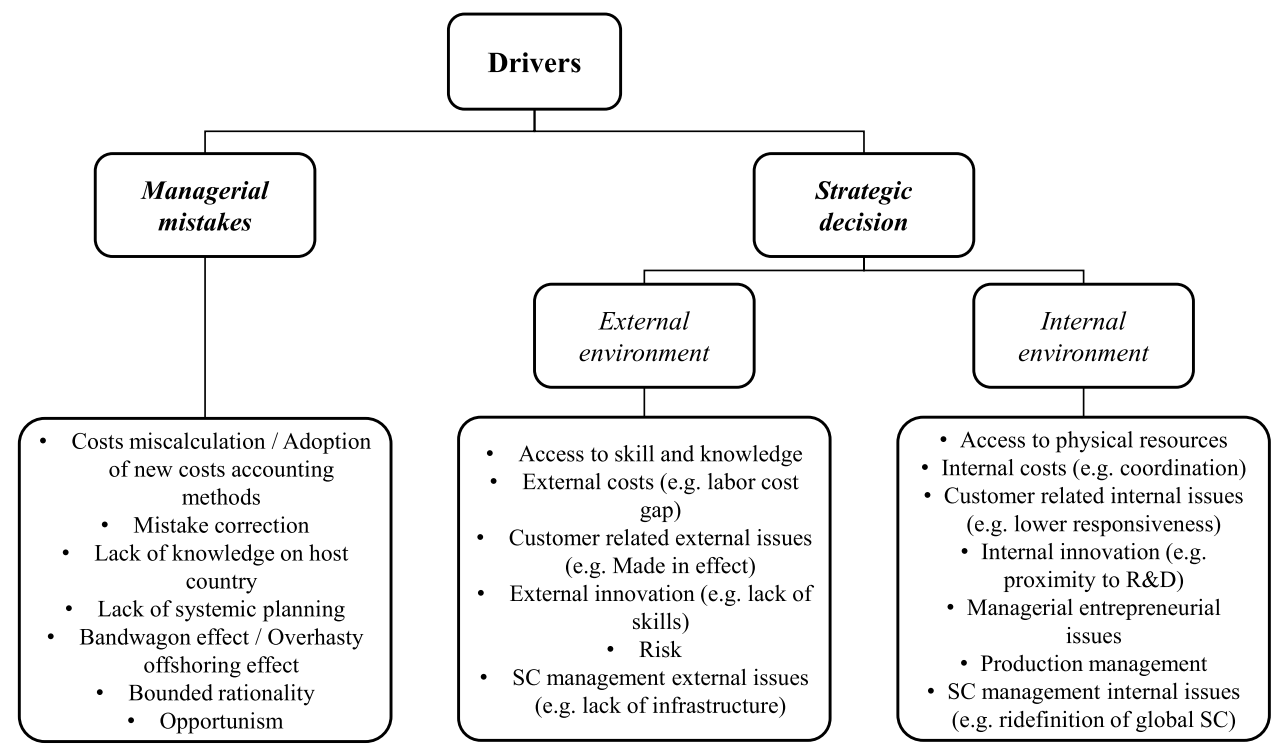

reshoring, namely decision-making, implementation and outcomes. Table 1 reports a description of these elements, which will be used to illustrate each case investigated in this research.

\subsection{Mistakes connected to reshoring}

Reshoring decisions are often conceptualized in the literature as a correction of previous errors made by the managers or entrepreneurs during the offshoring process, such as insufficient planning and lack of knowledge about the offshore location (Kinkel and Maloca 2009; Kinkel 2014). Barbieri et al (2018) in their literature review found that more than one-third of the articles were reporting some kind of managerial mistake drivers, with "miscalculation of actual cost and/or adoption of new cost accounting methods" being the most relevant. Coherently, Kinkel (2014) estimates from empirical data that only $20 \%$ of reshoring decisions made by German companies are mid- or longterm reactions to changes in the local environment, while the majority of them (around 80\%) are pure corrections of managerial mistakes. It is important to highlight that, even if reshoring literature used to refer to "managerial mistakes", this term might not reflect the errors and mistakes that may happen during a reshoring process, since multiple people might be involved, besides managers (Fratocchi and Silva 2018). Therefore, in this paper we will use the more general term "mistake", to indicate that we will consider any kind of mistakes happening along the reshoring process, independently from who is responsible for the mistake.

Management literature has addressed mistakes typically under the perspective of leadership failure (Van and Leslie 1995; Leslie and Velsor 1996). Authors have extensively addressed the reasons of bad management (McCall and Lombardo 1983; Hogan 1994; Hogan and Hogan 2002; Dotlich and Cairo 2003; Finkelstein 2004, 2005) typically

Table 1 Elements of the relocation process

\begin{tabular}{lll}
\hline Element & Description & References \\
\hline Decision-making & $\begin{array}{l}\text { All the aspects included in the decision, starting from the } \\
\text { motivations driving the relocation decision (including the } \\
\text { tipping point), coming to the specific product and activities } \\
\text { to be relocated, the location decision and the decision- } \\
\text { making process }\end{array}$ & $\begin{array}{c}\text { Bals et al. (2016); Foerstl et al. (2016); Fratocchi et al. } \\
\text { (2017); Boffelli and Johansson (2020) }\end{array}$ \\
$\begin{array}{l}\text { All the aspects related to how the reshoring decision can } \\
\text { be operationalized, such as governance mode, degree } \\
\text { of relocation, incremental or instantaneous process, } \\
\text { maintaining production at the domestic/foreign site, } \\
\text { information sharing and preparation activities }\end{array}$ & $\begin{array}{c}\text { Bals et al. (2016); Benstead et al. (2017); Boffelli and } \\
\text { The result connected to the relocation decision in terms of } \\
\text { benefits or problems, both in the short-term and in the } \\
\text { long-term }\end{array}$ & Foerstl et al. (2016); Boffelli and Johansson (2020) \\
Outcomes & &
\end{tabular}


classifying these as the results of unethical behaviour or due to lack of competences (Kellerman 2004). Several works have been focusing on the reasons why managers make wrong decisions leading to several possible sources such as routines (Nelson and Winter 1982), lack of experience and structure (Larsen et al. 2013), organizational complexity (Lundberg and Thompson 1967; Argyris and Schön 1997), lack of information (Finkelstein 2004, 2005), individual bias (Kahneman and Tversky 1984; Das and Teng 1999), failure to follow the clues and strong signals (Finkelstein 2004), the existence of a dominant logic (Prahalad and Bettis 1986), wrong or not well-defined goals (Cafferata 2016). Burke (2006) provides a rather comprehensive review of these factors.

Even though previous research found Small and Medium Enterprises (SMEs) being more subjected to making mistakes in the offshoring decision evaluation due to shortage of internal resources (Kinkel and Maloca 2009), the evidence here reported does not exclude larger companies from being exposed to similar mistakes. The literature on managerial mistakes points attention to "growth traps" (Argenti 1976; Smart and Vertinsky 1977; Abatecola 2019) that can lead larger companies to fail due to issues like dominant logic (Prahalad and Bettis 1986), failure to follow the clues and strong signals (Finkelstein 2004), lack of information (Finkelstein 2004), organizational complexity (Larsen et al. 2013).

Albertoni et al. (2017) suggest that managerial mistakes arise in all the cases in which firms experience hidden or unexpected costs during the offshoring period (Larsen et al. 2013), linked for example to coordination costs higher than expected or to more costly knowledge transfer. Moreover, they state that companies are more likely to reshore if they do not achieve satisfactory performance. Managers prefer to align themselves with success rather than failure and thus they are encouraged to withdraw from mistakes (Lee Fiona et al. 2004; Palmer et al. 2010), leading often to additional failures (Finkelstein 2004). Connected to this last point, Di Mauro et al. (2018) associated problems with operational performance to mistakes correction. Some authors have suggested that, given that the offshoring decisions are likely to be biased because of bounded rationality or behavioural heuristics, reshoring may represent a short-term mistake correction (Gray et al. 2017).

Despite a strong association between mistakes and outcomes have been identified, research has not been conducted yet, to the best of our knowledge, on how mistakes influence the success or failure of a reshoring strategy. Moreover, until now literature has assumed that mistakes only occurred during the decision-making, while implementation-related mistakes have not been considered by the literature. Even if previous literature on reshoring agrees in considering managerial mistakes behind the drivers of the relocation decision (Barbieri et al. 2018), to the best of our knowledge, no research has been conducted to better understand what kind of mistakes can occur along the decision-making and implementation process (Boffelli et al. 2020). Therefore, even if the three elements of the reshoring process, namely decision-making, implementation and outcomes, can be expected to be intertwined, a gap in previous research exists concerning how mistakes happened in each of the two phases of the reshoring process (decision making and implementation) influenced the outcomes of the process itself. This research candidates to fill this gap, by answering the following research question:

RQ1: What types of mistakes occur along the decisionmaking and implementation process?

Moreover, this paper aims to understand whether mistakes occurred in the company's history of relocation decisions - i.e., both during offshoring and reshoring - may affect the outcome, in terms of failure or success, of the relocation itself. Particularly, by looking at the decisionmaking and implementation processes of both offshoring and reshoring, we aim to assess the mistakes happened and how they influenced the success or failure of both decisions. Moreover, we will consider offshoring a failure if the company completely relocated to the home country, without leaving any activities or product lines in the host country, while reshoring will be considered a failure if the production in the home country was later transferred back completely to the host country or if the whole company went bankrupt. Therefore, the second research question is:

RQ2: How mistakes affect the outcome, in terms of success or failure, of a relocation strategy?

\section{Multiple-case study methodology}

Given the explorative aims of this paper and the willingness to dig deeper into cause-and-effect relationships, a multiple-case study methodology seemed an appropriate approach. This methodological perspective allows enriching knowledge regarding the reshoring phenomenon. More specifically, authors adopted the inductive case study methodology since this approach is particularly oriented towards exploration, discovery, and inductive logic (Patton 2002) and is recognised as appropriate to develop data grounded testable theories (Eisenhardt 1989; Voss et al. 2002).

To implement the chosen methodology, the research was designed around the following steps: a) cases selection, b) data collection, c) within-case analysis, d) cross-case analysis.

Concerning the selection of the cases, given the willingness to study the overall process from offshoring to reshoring, we selected the offshoring-reshoring process with the firm as a 
unit of analysis. Thus, case selection was focused on firms that already went through both the offshoring and reshoring, allowing the assessment of the outcomes. A homogeneous sampling approach (Patton 2002) was adopted, to ensure that variations are not caused by extraneous/confounding variables (Saunders et al. 2003). Four companies from the fashion industry have been selected as cases: two footwear companies from Italy and Portugal, one clothing company and one dyeing company both from Italy. The four companies differed in terms of the outcome of the reshoring process, as Pt-Shoes and It-Clothes were cases of failure, while It-Shoes and It-Yarns were cases of success. Table 2 summarises the main features of the sampled companies.

Data were collected through one semi-structured interview per case (the questions used as a basis for the semi-structured interviews are provided in Appendix A). The interviewees were the people that were directly involved in the reshoring decisions and that followed its implementation. Each interview lasted at least two hours with the involvement of at least two members of the research team. Interviews were recorded and fully transcribed. The collected information was supplemented with internal documents (e.g., project plans, reports, market performance, balance sheets) provided by the companies and with external secondary sources (e.g., press reports on the offshoring or reshoring initiatives), thus allowing to triangulate evidence (Eisenhardt 1989). Preliminary versions of the case studies reports were developed and sent back to the informants, to verify information accuracy. As a result of the feedback received, the final versions of the case studies reports were developed.

To reduce and categorize cases information, coding and data analysis were conducted manually and individually by researchers to ensure inter-coder reliability; after internal discussions and comparisons of codes, the inter-coder agreement reached 100\% (Duriau et al. 2007). The crosscase analysis has been implemented following the building blocks proposed by Boffelli and Johansson (2020), namely decision-making, implementation and outcomes, which allowed researchers to investigate and to compare both, the offshoring and reshoring strategies. Concerning the outcomes, we considered offshoring a failure if the company completely relocated to the home country, without leaving any activities or product lines in the host country, while reshoring was considered a failure if the production in the home country was later transferred back completely to the host country or if the whole company went bankrupt.

The rigour of the research was assured by adopting the strategies suggested by Yin (2003) and Eisenhardt (1989). To enhance construct validity, all researchers were on the same page in terms of literature background and were constantly involved in the different steps of the research. Besides, secondary sources were used for triangulation purposes, such as news, the companies' websites, balance sheet data. The internal validity was achieved thanks to the adoption of a pattern matching approach, which consisted of the construction of arrays summarizing cases data that enabled the comparison across cases of similarities and differences, and an iterative proposition development (Voss et al. 2016). The presence of multiple cases allowed to increase external validity, even if the choice to focus on a specific and known context may limit generalizability. Finally, reliability is ensured by the transparency of the adopted research process.

\section{Within case analysis}

\subsection{It-Shoes}

It-Shoes is a mountain shoe manufacturer located in a little village within the so-called "district of sportive shoes" of Montebelluna in North-Eastern Italy. The company was founded in 1979 as a handicraft shoes company. The

Table 2 Summary of cases

\begin{tabular}{|c|c|c|c|c|}
\hline Firms characteristics & It-Shoes & Pt-Shoes & It-Clothes & It-Yarns \\
\hline Product line & Mountain shoes & Dress shoes & Total look clothes & Dyed yarns for clothing \\
\hline Belonging to an industrial district & $\begin{array}{l}\text { Yes } \\
\text { (Montebelluna) }\end{array}$ & $\begin{array}{l}\text { Yes } \\
\text { (Felgueiras) }\end{array}$ & $\begin{array}{l}\text { Yes } \\
\text { (Treviso) }\end{array}$ & $\begin{array}{l}\text { Yes } \\
\text { (Bergamo) }\end{array}$ \\
\hline $\begin{array}{l}\text { Firm size (according to the European } \\
\text { Commission definition) }\end{array}$ & Small & Medium & Large & Medium \\
\hline Establishment year & 1976 & 1979 & 1965 & 1905 \\
\hline Offshoring year & 1999 & 2004 & 2000-2014 & 2004 \\
\hline Reshoring year & 2009 & 2010 & 2016 & 2011 \\
\hline Home country & Italy & Portugal & Italy & Italy \\
\hline $\begin{array}{l}\text { Host country (interested by the } \\
\text { reshoring decision) }\end{array}$ & Romania & Morocco & Croatia & Hungary \\
\hline Interviewee role & Entrepreneur & Entrepreneur & $\begin{array}{l}\text { Chief Operating Officer } \\
\text { (COO) }\end{array}$ & Entrepreneur and $\mathrm{COO}$ \\
\hline
\end{tabular}


production cycle was completely handmade and based on the technical skills of the entrepreneur and his employees. Since its establishment, the company occupied a niche market characterized by high-reliability and high-quality products. However, since the little number of sales of products with the owned brand, the entrepreneur decided to operate also as a contract manufacturer. In 1997, the company started a collaboration with a French group, which bought the company's brand the following year. The company then launched its own new brand continuing to supply the French client, which accounted for around $70 \%$ of total sales. Manufacturing activities have been always in-sourced while materials were supplied only by Italian partners since materials directly impact the perceived product quality.

Given the continued pressure by the French client to lower production costs, the entrepreneur decided to verify opportunities for offshoring production activities to Eastern Europe. He decided to relocate only the low- and mid-end product lines, mainly made for the main customer; the manufacturing of high-quality mountain shoes remained in-sourced in the home plant. Having implemented a "slicing offshoring" strategy, the company retained all machinery within the Italian factory, even if the production volumes were dramatically reduced.

Even though It-Shoes' production had been relocated to Romania considerably, thus reducing the final product cost, the French client continued to request further price reductions. Meeting these demands became impossible without implementing a "further offshoring" strategy addressed to even lower-cost countries (like China and South-East Asia). The entrepreneur evaluated it too risky. More specifically, he was worried by the increasing control problems that would have emerged after relocating production activities so far from the home location. Considered this huge risk, the entrepreneur understood that the only alternative for the firm's survival was changing its competitive strategy. More specifically, he decided to enlarge revenues of the firms' brand. However, the decision to focus on the own brand was no more compatible with the choice of locating the entire production process in Romania. In this respect, it must be noted that in the mountain shoes segment (and more generally in the shoes market) a product certified as "made in Italy" is associated by customers with a considerably higher value (Di Mauro et al. 2018). In the case of It-Shoes, such a better customer perception was supported by the firm's high reputation as a producer of cutting-edge technical mountain shoes gained by its highend product line. However, EU law states it is possible to certify a product as "made in Italy" only if the most value-adding production activities are performed in Italy. "Minor" production activities (like upper production) may remain offshore. Therefore, in 2009 It-Shoes relocated the assembling and finishing production phases to Italy, while leaving the "upper" production in Romania. The choice of not completely ending the production activities in the host country means that the offshoring decision cannot be considered as a failure. The reshoring decision was supported by the availability of spare production capacity in the home plant since machinery was not sold after the initial offshoring decision. The decision to partially reshore manufacturing activities was supported also by the entrepreneur's emotional attachment to Italy and the Montebelluna district. At the same time, he wanted to give his daughter, who was already involved in the company, the possibility to manage the business in Italy as It-Shoes changed hands from the first generation to the second.

However, the decision to relocate to the home county some of the production process phases was not so easy to be implemented since the main supplier in Romania declared not being interested in doing business with It-Shoes anymore since volumes were too small. This induced the entrepreneur to find a new supplier that would accept producing only semifinished products and in low volumes. With this respect, selection criteria related to product quality and lead-time were still relevant for the new choice of the supplier. Having evaluated various alternatives, the entrepreneur decided to sign a production partnership with another Romanian firm, which had produced within the Montebelluna district until 2001, when it completely relocated its production to Romania. The entrepreneurs and founders of the two companies were almost the same age and had known each other since the 1990s. At that time, the Romanian firm, still in Italy, acted as a supplier of It-Shoes for specific production phases or in case of peaks of market demand. This earlier relationship facilitated the implementation of It-Shoes' reshoring strategy. The entrepreneur of the Romanian company stated, "We developed a high level of synchronization, [...] even when It-Shoes develops a new model, it is easy to arrange the new production process".

The company production capacity was focused on "uppers" for shoes addressed to mountaineering, cycling, motorcycling and free climbing (the only product line sold with the company own brand) segments. For each of the three product lines manufactured as a supplier, the Romanian company decided to serve only one client. Therefore, It-Shoes was sure that the technical know-how transferred to the Romanian supplier was not at risk to be disseminated to other offshored competitors. As in the previous offshoring phase (when production was managed by the former Romanian supplier), the material supply of critical materials (e.g., leather, soles) was allocated to Italian suppliers.

In evaluating the offshoring experience, the entrepreneur of It-Shoes noted: "I went offshore also because of the politics of globalization. With hindsight, it was a mass mistake. But if 15 years ago I had not done it, I would not be here now. There was no other solution". 
It-Shoes sales are currently around 2 million $€$, of which only $20 \%$ still derives by contract manufacturing. Employees are around twenty and their average age is quite small since the entrepreneur decided to recruit new people after relocating manufacturing activities in Italy.

\subsection{Pt-Shoes}

Pt-Shoes has been for several years one of the top 10 footwear manufacturers in Portugal. It was founded in one of the two Portuguese regional clusters for the production of footwear. The company was initially focused on production for local private labels; however, in 2000-foreseeing the potential negative impact of China entering the World Trade Organization (WTO) - the founder's son decided to develop an owned-brand which was finally launched in 2002. With this respect, he declared "We tried to anticipate that entry [China's entry in the WTO], by trying to upgrade our competitive advantage. We knew we couldn't compete on the basis of low labour costs anymore and we already had a very good knowledge of the production of a good quality shoe".

In 1999 the company had experienced a severe shortage of skilled people in its home area because it had almost reached the full employment level. Given the lack of human resources, the company opened a new plant in another city in Portugal. After the launch of their brand, the two plants produced shoes for both the product lines (both private label and the owned brand).

At the beginning of 2000 , the company experienced a strong pressure by private label customers for lower prices; therefore, it firmly perceived the risk to lose contract manufacturing orders because of the intention of international customers to choose Chinese suppliers. Therefore, in 2004, the founder decided to open a new wholly-owned plant in Morocco, employing up to 100 people. After the new plant opening, the second plant opened in Portugal was shut down and employees dismissed.

Morocco was chosen for several motivations; among them, the most relevant were the lower labour costs and the geographical proximity. At the same time, it was expected that skilled people were locally available; finally, the language was not considered as an obstacle as most Moroccan people spoke French, and Pt-Shoes' entrepreneurs as well. The Moroccan site was mostly dedicated to the manufacture of "uppers", the most labour-intensive production phase. However, in case of demand peaks, the plant was requested to produce also entire shoes, but only for private labels since the production of branded high-quality shoes with the firm's trademark remained at home.

In the following six years, the firm experienced several troubles with its production site in Morocco. First, even though Moroccan wages were lower than Portuguese ones (around a half), local employees were highly unionised and had lower productivity. With this respect, one needs to consider frequent production stops due to religious issues (observant Muslims are requested to pray five times a day and even seven during the Ramadan period when productivity levels are further reduced due to fast). Summing up, the entrepreneurs realised that productivity in Morocco was at least $30 \%$ less than in Portugal, an issue was not carefully evaluated when taking the offshoring decision. Additionally, the managers realised that there were some issues concerning the money transfer from one country to the other, with delays and taxes to be considered. A second motivation inducing the company to relocate production activities at the home country is related to the psychic distance; while the language was not a barrier, the company discovered the Moroccan mental framing was different from the Portuguese one. More specifically, the entrepreneur's son noted: "We understood the attitude towards work to be much more radical than the one normally displayed by Portuguese people. They [Moroccan workers] overreact a lot and have not much patience". Moreover, the local middle managers were generally not collaborative and preferred to support workers' criticisms instead of explaining the mother company's requests. However, the manufacturing reshoring decision was mainly the consequence of the "family succession" within the company that is when the entrepreneur's son replaced his father as CEO. After this deal, the large-scale production business model previously implemented was completely substituted. The product valueadded was hugely increased and the firm's brand became pivotal in the company strategy. Consequently, the product lines were enlarged in terms of models and colours and new production techniques were implemented. However, while production lots become smaller, it was hard to imprint the necessary rhythm within the Moroccan facility. Therefore, in 2010, the new CEO decided to completely relocate in Portugal all the manufacturing activities, thus reflecting the failure of the offshoring strategy. In evaluating the offshoring experience, the entrepreneur summarized his mind saying "I can consider that as a disappointing experience [...] We have been in Morocco for six years in total and it was a pity that we didn't realise before that the decision to close should be taken. We waited too long to decide to fully concentrate our operations again in Portugal". After the Moroccan site closure, production activities were re-transferred to the same place where the company had opened the second plant in the 1990s. Fortunately, people earlier discharged were all still available in the local labour market and Pt-Shoes was able to re-establish their normal activity soon after.

After a huge growth of its total sales-around 12 million $€$, equally distributed among the two product lines - and exports (around $95 \%$ of own branded shoes had been sold in 800 sales points located in more than 20 foreign markets, ranging from EU to North America, Australia, and Japan), 
in April 2018 the CEO decided to liquidate the company. In the end, this shows that not even the reshoring strategy can be considered a success.

\subsection{It-Clothes}

It-Clothes was founded in 1965 as a family firm in Northern Italy, in one of the most important industrial districts for textiles in Italy, the Treviso textile district. In those days, the production activities were completely developed in house, and for almost 30 years the production, partially through contract manufacturing, remained in Italy. Between the end of the 1990s and the beginning of the 2000s, the company started to offshore (and outsource) production activities mainly in Europe. The offshoring decision was taken by the board of directors, that mainly included family members. The offshoring and outsourcing process ended in 2014 when It-Clothes was only buying final products; it was part of a change in the company's strategy from being a manufacturer to becoming a retailer with a recognizable brand. All the production sites opened, initially owned by It-Clothes, were progressively sold to a company controlled by the same holding that was also controlling It-Clothes. From time to time, the company was still outsourcing some activities to Italian firms, but only in case of very innovative processes (e.g., stone wash, vegetable dyeing). For It-Clothes the offshoring and outsourcing strategy was a strategic choice to focus on the highest value-adding activities and the brand valorisation. In 2016, It-Clothes decided to start a small relocation project by buying some machinery back from the Croatian plant of the "sister" company and bringing them back to Italy, but without closing any foreign plant. This means that the offshoring strategy was not considered a failure by the company. The reshoring decision was made by the Chief Executive Officer (CEO) but, along the decision-making process, also the Chief Operating Officer (COO) and many company departments were involved (namely, marketing and communication, sales, and R\&D) The machinery was based on a cutting-edge technology that allowed It-Clothes to introduce a new seamless sweater on the market and to take advantage of the lower labour intensity of the process. Of course, all the suppliers of raw materials for this product were Italian, so to obtain a fully "Made in Italy" product. Besides trying to leverage on the "Made in Italy" features of the new products, other reasons that pushed It-Clothes to reshore were the higher automation (and lower labour intensity) connected to the new technology, the possibility to develop new and lost know-how, the higher synergies between production and research and development, the higher service level that was possible to guarantee to the customer, and the company's image strengthening opportunity.

Given the small scale of the new sweater production, only a few shops were selling it and at a higher price with respect to a comparable sweater sold in the same shop and produced with a different technology outside of Italy. Therefore, for what concerns the marketing of the product, It-Clothes failed in making the characteristics of the new product evident, such as being "Made in Italy", part of a relocation project and produced with cutting-edge technology. Even if, in a first period, the company benefitted of a return in terms of improved firm's image in front of the mass media and of its employees, the reshoring project was ended soon, given the low appreciation of the new product by the market. Interestingly, the company, starting from 2017, has experienced a constant reduction in its sales, nowadays equal to 878 million $€$. Instead, the number of employees has constantly increased from 2011, even if with a reduced slope in more recent years. Nowadays, the company employs more than 3000 people. This further show the failure of the reshoring strategy. Moreover, the company has always been convinced about the correctness of the offshoring choice, as proven by the COO's words: "Made in Italy is fundamentally accessible in a difficult way for the company because obviously, the cost of manufacturing is high... we can also find suppliers abroad that do everything we need, and I have to say that over the years the logistics costs have been reduced."

\subsection{It-Yarns}

It-Yarns was founded as a producer of colourants and chemicals for the textile industry by an Italian family in 1905. After almost 10 years in Milan, the company moved its activities within the textile district of Bergamo and opened new departments for dyeing activities. Nowadays the company is the leader in terms of volume in Europe and differentiate from its competitors thanks to the product quality and the high service level. Over the years, the company and its major customer became very closely tied, almost $40 \%$ of It-Yarns' turnover was generated by this customer. Driven by the need to look for lower production costs, the two companies together acquired a plant in Hungary in 2004. The acquisition allowed the companies to maintain some major customers looking for lower prices and to integrate production activities that were previously outsourced. It-Yarns was producing the basic colours and lower-end yarns at a lower production cost in the offshore plant. In 2011, the customer and partner of It-Yarns decided to further offshore to Egypt in search of even lower costs. At that point, It-Yarns had to decide whether to maintain the Hungarian plant by its own or to relocate back to Italy. At first, the company was looking for alternative partners because the plant needed new investments to buy newer machinery. When the company realized that it was not possible to find a new partner in a short time, the entrepreneurs, the three brothers that inherited the company's ownership and management, decided together to relocate to the home country. The decision to completely move back activities reflects the failure of the offshoring 


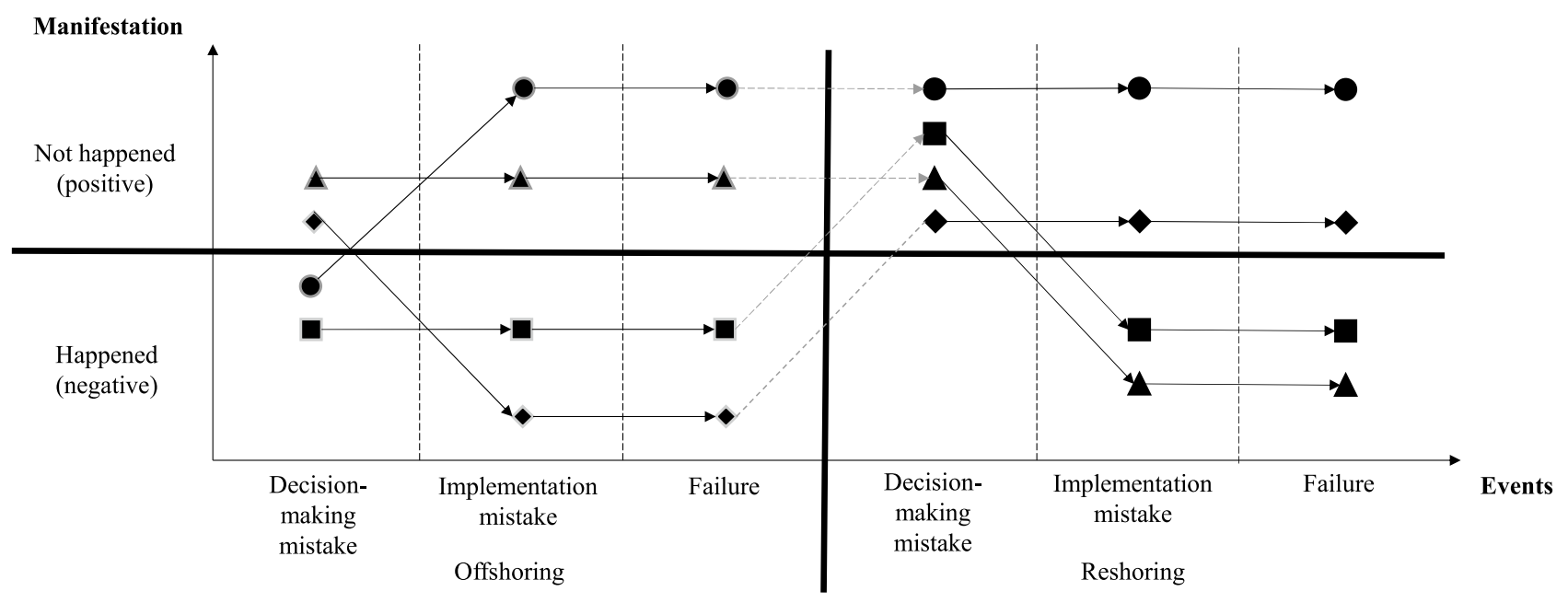

Legend
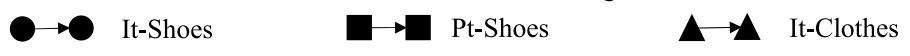

$\leadsto$ It-Yarns

Fig. 2 Comparison of relocations in terms of mistakes and failures manifestations

strategy. The products made in the Hungarian plant were moved back to Italy, where free capacity was available and where the advanced competencies allowed to quickly understand the slightly different production process followed at the Hungarian plant. This decision allowed the company to maintain the customers that had been served from Hungary but providing higher quality and a better service level. As explained by the entrepreneur, the company well assessed the decision to bring production back to its Italian plant: "It was decided to return production in the Italian factory after having carried out a performance analysis, thanks to which we could see that the Italian branch would have been able to produce the part of the production that was made in Hungary, without having any particular capacity problems". After the reshoring decision and its implementation, the company has reported steady sales of around 9 million $€$ and a slight reduction in the number of employees. Today, the company sells around 6 million $€$ and employ around 60 employees, 35 people less than in 2011. All in all, the reshoring strategy was considered a success by the company, while the lower economic results were attributed to the global downturn of the industry. Nowadays, It-Yarns is still strongly collaborating with its major customer, the decision to follow the customer in the offshoring initiative was inevitable to maintain a good relationship and to further strengthen it.

\section{Cross-case analysis}

The cross-case comparison aims to compare both the offshoring and reshoring strategies of the four studied companies, to define commonalities and differences. To properly compare and contrast the cases, as aimed with the cross-case analysis, the three building blocks of the relocation processes identified by Boffelli and Johansson (2020) are detailed both for offshoring and reshoring for each case. In the end, whether and where mistakes happened is highlighted. Table 3 reports the details of the cross-case analysis.

By comparing the cases, we can see that mistakes are not only happening during the decision-making, but also at the implementation stage of the relocation (i.e., offshoring and reshoring) processes. While cases It-Shoes and Pt-Shoes report mistakes at the decision-making stage of the offshoring process, all the cases, except It-Shoes, report mistakes at the implementation stage either for offshoring or reshoring. In particular, It-Shoes decided to offshore on the wave of a bandwagon movement of similar companies to Romania and by addressing the pushing requests from the main customer, without considering the importance of investing on the owned brand to keep the margins high enough to make the business profitable and autonomous from someone else's decisions (i.e., wrong decision-aking). Pt-Shoes made a similar error leveraging on a low-cost strategy in a period in which differentiation could have made the difference to strengthen its brand and survive a possible future crisis (i.e., wrong decisionmaking). Implementation mistakes are instead related to a lack of the ability to manage the relocation, i.e., offshoring or reshoring, project. First, it is possible to recognize the presence of mistakes during the offshoring implementation of It-Yarns since it lacked in making the right investments to renew machinery from the beginning and had to renounce to the Hungarian plant once the main partner and customer decided to invest in Egypt. Pt-Shoes, instead, did not consider the lower productivity of the workers in Morocco, 


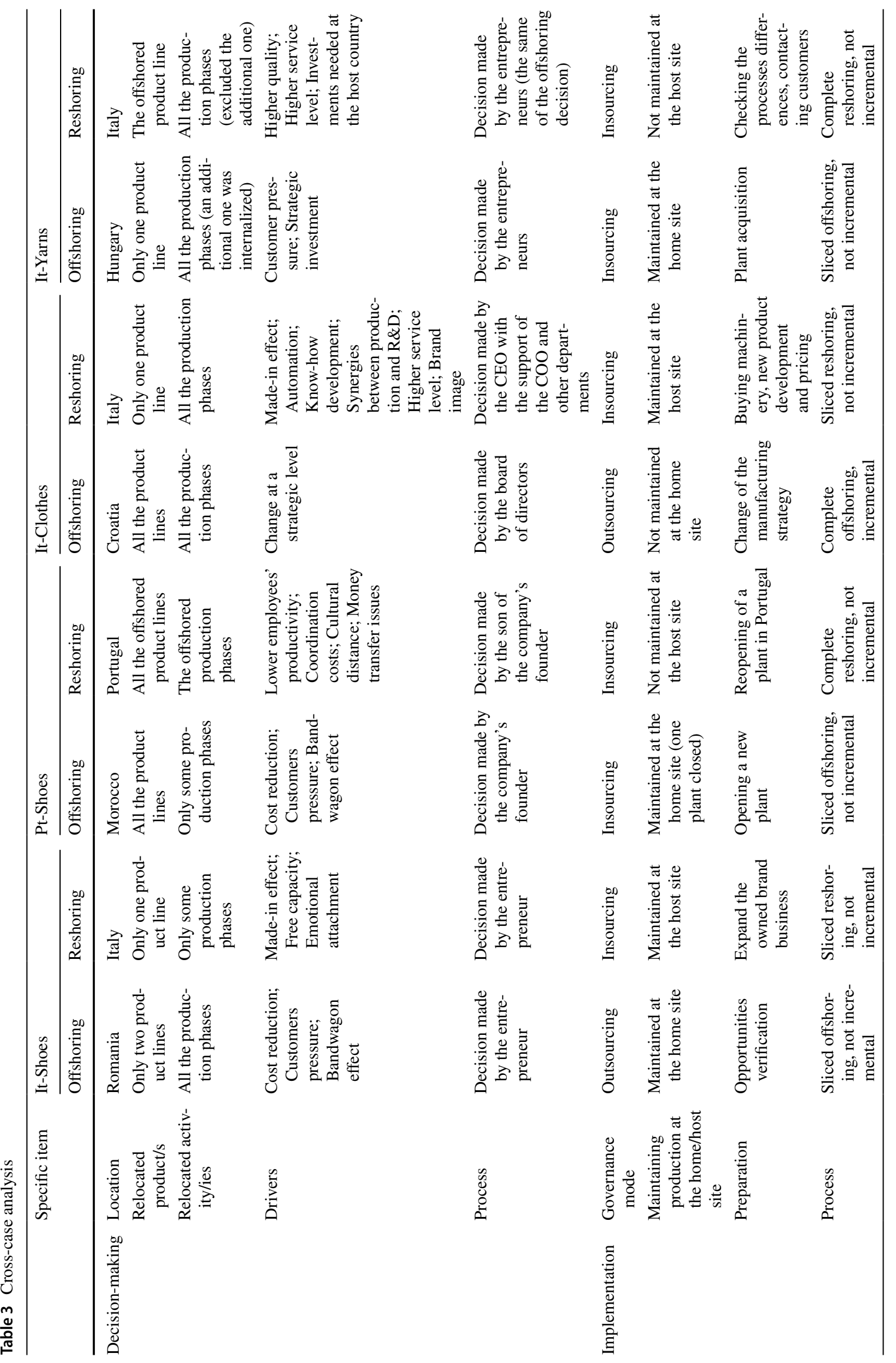




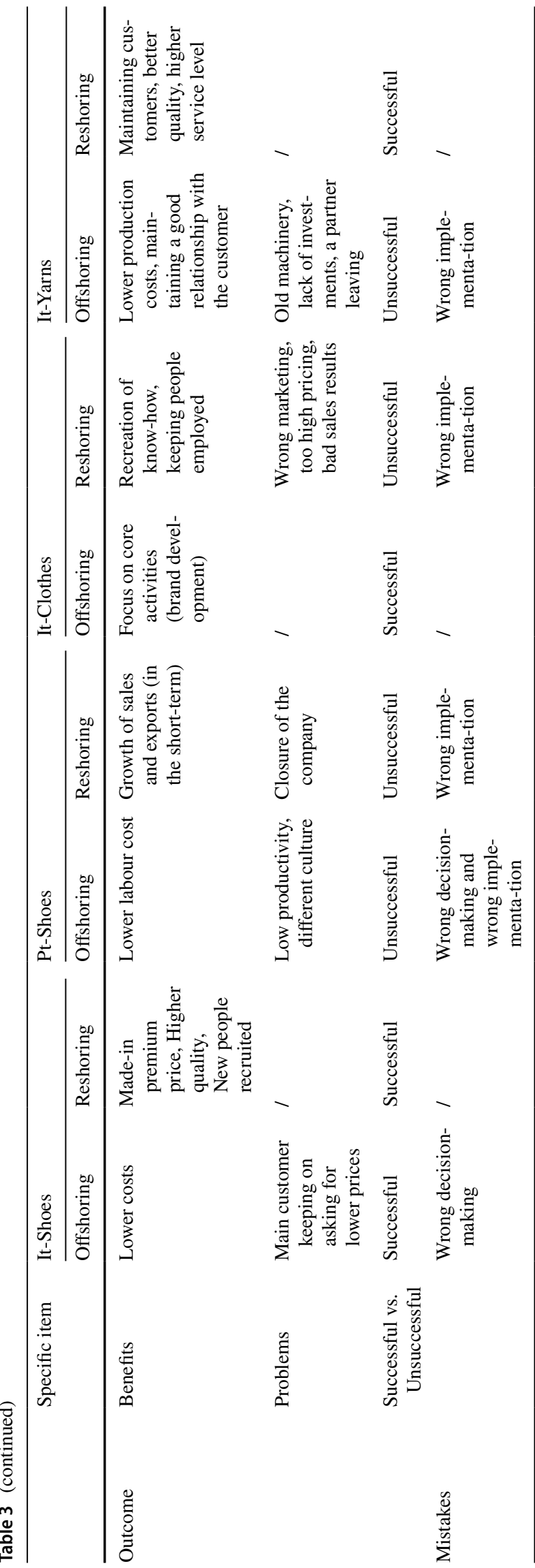

thus expecting a different performance from the offshore activity. Moreover, the company lacked in considering the different culture and to plan proper actions to assure better integration. Pt-Shoes experienced mistakes in the implementation of reshoring too, for which the hope to simply undo the previous decision was not enough to make it successful. Also, It-Clothes implemented the reshoring in a wrong way, by missing the opportunity to capture the value of the Made in Italy brand by selecting a wrong price for the new product and by lacking to define a proper marketing campaign.

This distinction between mistakes at the decisionmaking or the implementation stage allows understanding what the unsuccessful cases, either in the offshoring or reshoring, have in common. All of them share a wrong implementation, independently on what happened during the decision-making or, in case of reshoring, during the previous offshoring process. Figure 2 represents the commonalities between successful (in the upper part of the figure, namely the "Not happened" row) and unsuccessful (in the bottom of the figure, namely the "Happened" row) cases. What happened during the implementation makes the difference.

In the next section, these results are further discussed.

\section{Discussion}

The results from the cross-case analysis, allow us to provide answers to our exploratory research questions. The first research question tackled in this study was "What types of mistakes occur along the decision-making and implementation process? " The empirical results allow to further develop the acquainted conceptualization that distinguishes between reshoring as a correction of mistakes or as a strategic shift in response to changes in either internal or external environment (Barbieri et al. 2018). Results show that besides the mistakes related to decision-making, an additional class of mistake, related to implementation, need to be brought to the attention of researchers and practitioners. Thus, the first proposition emerging from this research is:

RP1: In the context of manufacturing relocations, mistakes need to be further distinguished between decision-making mistakes and implementation mistakes.

Particularly, from the cases hereby presented we can list some examples of both decision-making mistakes and implementation mistakes. Even though this list does not pretend to be comprehensive, it helps in reaching a better understanding of the two concepts.

Decision-making mistakes are usually derived from the uncertainty and complexity intrinsic to the relocation 
decisions that often lead decision-makers to bounded rational decisions (Gray et al. 2017; Boffelli et al. 2018, 2020). As reported in the cross-case analysis, It-Shoes offshored to Romania by imitating its competitors and to address the requests from its major customer, thus failing to invest in its owned brand and increase its market share. Pt-Shoes made a similar error leveraging on a low-cost strategy instead of differentiating its offer with a competitive brand. Examples of implementation mistakes are instead provided by Pt-Shoes, which did not consider the lower productivity of the workers in Morocco, the international money transfer, and the challenges connected to the integration in a different culture; or by It-Clothes, which failed to plan a proper marketing campaign, was not able to control the ongoing project and recognized its own mistakes with the product pricing.

The nature of mistakes seemed also to influence the "content" (products and activities) of the reshoring initiative; in fact, differences emerge among the four companies. Particularly, while relocating at the home country, both Pt-Shoes and It-Yarns decided to close the offshore plant interrupting every manufacturing activities. On the contrary, It-Shoes and It-Clothes decided to maintain abroad some manufacturing activities. It-Shoes continued to produce uppers in Romania, even if with a new supplier, since their high impact on total production costs and the low one on the product perceived value. It-Clothes, instead, brought back to Italy only a specific product in a small volume. Therefore these companies showed selectivity either in terms of width (meaning that specific product lines were relocated) or in terms of depth (meaning that specific production activities were relocated), according to Di Stefano et al. (2018). What differentiates the two clusters of companies is the type of committed mistakes. The two companies that decided to completely relocate to the home country (IT-Yarns and Pt-Shoes) and not to apply a selective reshoring (Baraldi et al. 2018; Di Stefano et al. 2018), made mistakes in the offshoring implementation. The above discussion leads to the following propositions:

RP2a: Reshoring deriving from mistakes connected to offshoring implementation involves all production lines and production phases earlier offshored.

RP2b: Reshoring may be selective, both in terms of width and depth, in case mistakes were not occurring during offshoring or were connected only to offshoring decisionmaking.

Concerning motivations that pushed the investigated companies to relocate production activities, they do not seem to be connected to the nature of mistake or the success of the relocation decision. In this respect, the first relocation decision (offshoring) has been boosted in the two shoesmaking companies by the search of lower costs (especially labour ones). This is consistent with earlier studies on the industry (Camuffo et al. 2006; Verdu et al. 2012; MartínezMora and Merino 2014; Di Mauro et al. 2018). The second main common motivation for the relocation decision was the customers' pressure for lower prices since both were contractors mainly. Finally, a third relevant driver explains the offshoring decision of both companies: the so-called "mimetic behaviour" (Silva et al. 2018), that is the imitation of strategies already implemented by other companies operating in the same industry and especially in the same industrial district (also known as "bandwagon effect"). Instead, for It-Clothes the main reason behind the offshoring decision was a change in the company's strategy that was shifting from being a manufacturer to becoming a retailer. Of course, production costs (including labour) made the difference in the choice of the locations. Finally, It-Yarns was seizing an investment opportunity with its major customer, even if the pressure of the customer played a role in influencing the decision. To summarize, while the first two companies (It-Shoes and Pt-Shoes) were looking for cost advantages, the latter two (It-Yarn and It-Clothes) were driven by more strategic purposes. Even if they were not sharing similar offshoring drivers, Pt-Shoes and It-Yarn were the two companies that made implementation mistakes that brought to unsuccessful offshoring. Concerning the motivations behind reshoring, Pt-Shoes and It-Yarns closed the offshore plants and moved production back to the home country as a reaction to the mistakes committed during the offshoring phase, namely concerning both decision-making and implementation in the case of Pt-Shoes, only implementation in the case of It-Yarns. On the contrary, It-Shoes and It-Clothes decided to repatriate only specific parts of the production activities, as in the It-Shoes case, or a specific product, as in the It-Clothes case. In both cases, reshoring was part of a bigger strategy to leverage on the "Made in Italy", thus gaining higher margins. Besides, it must be noted that, for It-Shoes, the reshoring decision was taken when the entrepreneur understood that the pressures for a lower price by the main customer were impossible to meet without a further offshoring strategy, an option the entrepreneur considered impossible to pursue. In the case of reshoring, Pt-Shoes and It-Yarns reacted to managerial mistakes, while It-Shoes and It-Clothes relocated because of strategic changes. Also, in this case, a common pattern cannot be identified, since Pt-Shoes and It-Clothes made implementation mistakes, thus resulting in an unsuccessful reshoring. The above discussion leads to the following proposition:

RP3: The drivers of relocation decisions do not influence the type of mistakes committed and the success of the relocation.

The second question this study aimed to address was "How mistakes affect the outcome, in terms of success or failure, of a relocation strategy?". The results from the 
multiple-case study show that it is the implementation that makes the difference in relocations. Even cases in which the decision was right, resulted in unsuccessful relocation if the implementation was not properly managed (e.g. It-Yarns' offshoring, Pt-Shoes' and It-Clothes' reshoring). Vice versa, wrong decisions might be turned into successful relocations if implemented well (e.g. It-Shoes' offshoring).

Thus, a research proposition can be advanced from the insights hereby presented:

RP4: To make a relocation decision successful, it is more important to correctly implement the decision rather than make the right decision.

This proposition and the connected results further highlight the relevance of the implementation and all the connected activities in manufacturing relocations, even though they have been mainly addressed conceptually until now (Bals et al. 2016; Barbieri et al. 2018).

Finally, one result that needs to be highlighted is the lack of path dependency between offshoring and reshoring when it comes to both the type of mistakes and the success of the relocation initiative. This result is somehow contrasting with previous literature that claimed the presence of path dependency between offshoring and reshoring (Kinkel 2012) and reported results aligned with such hypothesis with respect, for example, to the entry mode (Wan et al. 2019) and drivers (Barbieri et al. 2019). Kinkel (2012) provided results supporting the claim that the experience with previous relocations matters, thus suggesting that companies rely on "already practiced and well-rehearsed behavioural patterns and strategies, using existing interpersonal links and organizational routines" (Kinkel 2012, p. 712). This evidence seems not to be supported by our results since they show that companies experiencing an offshoring decisionmaking affected by mistakes; while reshoring, either make mistakes in implementation or do not make mistakes at all. Also, failure in offshoring does not necessarily mean failing the reshoring strategy too. To conclude, the last research proposition emerging from our study is the following:

RP5: Reshoring does not show path dependency features when it comes to the type of mistakes and the success of the relocation initiative.

\section{Conclusions}

This study aimed to understand what types of mistakes can occur along with the decision-making and implementation processes and whether how mistakes occurred in the company's history of relocation decisions - i.e., both during offshoring and reshoring - affect the outcome, in terms of failure or success, of the relocation strategy. Given the explorative nature of the research, a multiplecase study approach was adopted by focusing on four companies operating in the fashion industry. More specifically, both successful and unsuccessful cases have been compared. We analysed four cases that covered all the possible combinations of either successful or unsuccessful offshoring and either successful or unsuccessful relocations: namely both successful, both unsuccessful, successful offshoring but unsuccessful reshoring, and unsuccessful offshoring but successful reshoring. The comparison of these cases and the analysis of similarities and differences among them allowed us to find patterns to be linked to the results of the relocations. In the end, six propositions that explain our results ideally to be tested in future research have been developed. To the best of our knowledge, this is the first attempt to look at cases of failures in the context of reshoring and we believe this created new insights that could not emerge from the analysis of only successful cases. We have been able to further distinguish mistakes related to the decision-making from those related to the implementation. The latter emerged as having a relevant impact on the success of the relocation, both in case of offshoring and reshoring. This result generates an important contribution to the literature on reshoring and manufacturing relocations in general, since it brings the attention to the importance of this distinction, further supported by the relevance of implementation mistakes in explaining the failure of relocation initiatives. The latter evidence supports the strong entanglement among the phases of a relocation process, particularly when it comes to implementation and outcomes. Furthermore, this paper contributes to the debate on reshoring, in so doing, it confirms the usefulness of the suggestion to investigate the dichotomous conceptualization of reshoring (Bals et al. 2016), either as a correction to a previous mistake (Kinkel and Maloca 2009; Ellram et al. 2013; Kinkel 2014) or as a reaction to changes in the firm's external or internal environment (Martínez-Mora and Merino 2014; Fratocchi et al. 2016).

The findings hereby presented generate implications for both managers, and decision-makers in general, and policymakers. From our study managers derive the indication that doing the things right is more important than doing the right thing. The failure of relocation initiatives emerged to be directly connected to mistakes made in the implementation phase. Reshoring literature already recognized that reshoring decisions might be subjected to complexity (Boffelli et al. 2020) and uncertainty (Gray et al. 2017), however, even if decisions might be made in such a context, focusing on making plans and check the correctness of the implemented actions might turn even wrong decisions into successful relocations. Some 
tools were developed in the past to support reshoring implementation, such as the Reshoring Guidebook provided by the US-based consultancy company Reshoring Institute (Blue Silk Consulting 2014). Although, these tools are usually developed to fit a specific geographical context, characterized by specific incentives and governmental support. Instead, we suggest managers to rely on transversal project management tools and capabilities that would allow to manage even a relocation project effectively and efficiently. Besides this, defining a project manager, with recognized responsibility, and providing him/her a team with both technical and project management capabilities would drastically increase the success of any relocation strategy.

These findings are in line with several organizational theories that challenge the concept of strategy and rational decision making (Cohen et al. 1972; Mintzberg 1978; Weick 1995). Often strategy is more the ex-post interpretation of subsequent decisions rather than a clear ex-ante statement of what organizations aim to achieve. In this perspective, any decision will not lead to good results without proper implementation; on the contrary, if the wrong decision is well implemented, it will still allow organizations to obtain positive results, often influencing to a great extent the future of the companies' strategy.

Concerning policymakers, this paper informs them about the importance not only to push companies in deciding to bring manufacturing back but also in supporting them during the implementation of such a decision, so to have a successful reshoring. In this respect, we believe, and our cases confirmed it, that the highest relevance lies on building adequate conditions to bring manufacturing activities back, such as the availability of skilled human resources, as already noted in other contributions related to the fashion industry (see, among others Anson 2016; Bettiol et al. 2017; Boffelli et al. 2020).

Besides the insights and the implications generated by this research, several limitations must be acknowledged. First, it is focused on a specific context, namely the fashion industry and Europe. The considered companies belong to European Union countries, which share some commonalities in terms of production systems, especially for the investigated industry. Therefore, our conclusions may not be generalized to different contexts. The study relies on four cases, two success and two failure cases allowing us to generate a theoretical contribution. Nevertheless, we believe that expanding the analysis with additional case studies, especially in the case of unsuccess, would generate further insights going in a theory refinement and expansion direction (Silva and Silva 2012). This prompt for future large-scale research, allowing to test the validity of the hereby advanced propositions.

\section{Appendix A - The semi-structured interview protocol}

- Section 1: General information about the company and the interviewees

Interviewees: Names, roles, experience.

Company: Number of employees, turnover, main products, number, and location of plants.

- Section 2: Evolution of the manufacturing footprint

Main steps over years in terms of relocations and changes in governance modes

Focus on one (or more) reshoring decision(s):

- Chain of events connected to the reshoring decision(s)

- Products/Activities/Supply Chain involved and their characteristics

- Objectives, Drivers of the decision(s), Enabling factors, Outcomes

- Section 3: Decision-making stage

Description of the decision-making and timing

Phases, stakeholder involved, collected information, risks evaluated

Differences with previous offshoring

- Section 4: Implementation stage

Description of the implementation and timing

Phases, stakeholder involved

Changes in the relationships with stakeholders after reshoring

Learning process, criticalities faced, costs and benefits Differences with previous offshoring

- Section 5: Outcomes

Outcomes of offshoring

Outcomes of reshoring

Acknowledgements The authors thank the entrepreneurs and managers interviewed for their kind collaboration and the valuable information they made available. In addition, the authors thank the Editor, the Area Editor and the Reviewers involved in the revision process for their constructive

Author contributions All the authors contributed equally to all the phases of the study development, from study conception and design until writing and revision. All authors read and approved the final manuscript. 
Funding Open access funding provided by Università degli studi di Bergamo within the CRUI-CARE Agreement. The research was not funded by external entities.

Open Access This article is licensed under a Creative Commons Attribution 4.0 International License, which permits use, sharing, adaptation, distribution and reproduction in any medium or format, as long as you give appropriate credit to the original author(s) and the source, provide a link to the Creative Commons licence, and indicate if changes were made. The images or other third party material in this article are included in the article's Creative Commons licence, unless indicated otherwise in a credit line to the material. If material is not included in the article's Creative Commons licence and your intended use is not permitted by statutory regulation or exceeds the permitted use, you will need to obtain permission directly from the copyright holder. To view a copy of this licence, visit http://creativecommons.org/licenses/by/4.0/.

\section{References}

Abatecola G (2019) Reviewing Corporate Crises: A Strategic Management Perspective. Int J Bus Manag. https://doi.org/10.5539/ijbm.v14n5p21

Albertoni F, Elia S, Massini S, Piscitello L (2017) The reshoring of business services: Reaction to failure or persistent strategy? J World Bus 52:417-430. https://doi.org/10.1016/j.jwb.2017.01.005

Anson R (2016) Editorial: Reshoring-A renaissance for the textile and apparel industries in advanced economies or a passing fad? Text Outlook Int 180

Argenti J (1976) Corporate planning and Corporate Collapse. Long Range Plann. https://doi.org/10.1016/0024-6301(76)90006-6

Argyris C, Schön DA (1997) Organizational Learning: A Theory of Action Perspective. Rev Esp Invest Sociol. https://doi. org/10.2307/40183951

Bals L, Kirchoff JF, Foerstl K (2016) Exploring the reshoring and insourcing decision making process: toward an agenda for future research. Oper Manag Res 9:102-116. https://doi.org/10.1007/ s12063-016-0113-0

Baraldi E, Ciabuschi F, Lindahl O, Fratocchi L (2018) A network perspective on the reshoring process: The relevance of the home- and the host-country contexts. Ind Mark Manag 70:156-166. https://doi. org/10.1016/j.indmarman.2017.08.016

Barbieri P, Ciabuschi F, Fratocchi L, Vignoli M (2018) What do we know about manufacturing reshoring? J Glob Oper Strateg Sourc 11:79-122. https://doi.org/10.1108/JGOSS-02-2017-0004

Barbieri P, Elia S, Fratocchi L, Golini R (2019) Relocation of second degree: Moving towards a new place or returning home? J Purch Supply Manag 25

Benstead AV, Stevenson M, Hendry LC (2017) Why and how do firms reshore? A contingency-based conceptual framework. Oper Manag Res 10:85-103. https://doi.org/10.1007/s12063-017-0124-5

Bettiol M, Burlina C, Chiarvesio M, Di Maria E (2017) Industrial district firms do not smile: Structuring the value chain between local and global. In: Devinney TM, Tihanyi L, Camuffo A (eds) Pedersen T. Opportunities and consequences. Emerald Publishing Limited, Breaking up the Value chain, pp 269-291

Blue Silk Consulting (2014) The Reshoring Guidebook

Boffelli A, Golini R, Orzes G, Dotti S (2020) Open the box: A behavioural perspective on the reshoring decision-making and implementation process. J Purch Supply Manag

Boffelli A, Golini R, Orzes G, Dotti S (2018) 'How to Reshore': Some evidence from the apparel industry. IEEE Eng Manag Rev. https:// doi.org/10.1109/EMR.2018.2886183
Boffelli A, Johansson M (2020) What do we want to know about reshoring? Towards a comprehensive framework based on a metasynthesis, Oper Manag Res

Burke RJ (2006) Why leaders fail: Exploring the darkside. Int J Manpow. https://doi.org/10.1108/01437720610652862

Cafferata R (2016) Darwinist connections between the systemness of social organizations and their evolution. J Manag Gov. https://doi. org/10.1007/s10997-014-9303-Z

Camuffo A, Furlan A, Romano P, Vinelli A (2006) The process of supply network internationalisation. J Purch Supply Manag 12:135-147

Cohen MD, March JG, Olsen JP (1972) A Garbage Can Model of Organizational Choice. Adm Sci Q. https://doi. org/10.2307/2392088

Das TK, Teng BS (1999) Cognitive biases and strategic decision processes: An integratwe perspective. J. Manag, Stud

Di Mauro C, Fratocchi L, Orzes G, Sartor M (2018) Offshoring and backshoring: A multiple case study analysis. J Purch Supply Manag 24:108-134. https://doi.org/10.1016/j.pursup.2017.07.003

Di Stefano C, Fratocchi L, Merino F (2018) Manufacturing relocations in the footwear industry: A comparison between Italy and Spain. Adv Manuf Technol XXXII 455-460

Dotlich DL, Cairo PC (2003) Why CEOs Fail : The 11 Behaviors That Can Derail Your Climb to the Top-and How to Manage Them / David L. Cairo; Forewords by Ram Charan and Robert Hogan, Dotlich, Peter C

Duriau VJ, Reger RK, Pfarrer MD (2007) A content analysis of the content analysis literature in organization studies: Research themes, data sources, and methodological refinements. Organ Res methods 10:5-34

Ellram LM, Tate WL, Petersen KJ (2013) Offshoring and reshoring: an update on the manufacturing location decision. J Supply Chain Manag 49:14-22. https://doi.org/10.1111/jscm.12019

Eisenhardt KM (1989) Building Theories from Case Study Research. Acad Manag Rev 14:532-550. https://doi.org/10.5465/ AMR.1989.4308385

Finkelstein S (2005) When bad things happen to good companies: Strategy failure and flawed executives. J Bus Strategy 26:19-28. https://doi.org/10.1108/02756660510586300

Finkelstein S (2004) Why smart executives fail: and what you can learn from their mistakes

Foerstl K, Kirchoff JF, Bals L (2016) Reshoring and insourcing: drivers and future research directions. Int J Phys Distrib Logist Manag 46:492-515. https://doi.org/10.1108/IJPDLM-02-2015-0045

Fratocchi L, Ancarani A, Barbieri P et al (2016) Motivations of manufacturing reshoring: an interpretative framework. Int J Phys Distrib Logist Manag 46:98-127. https://doi.org/10.1108/IJPDLM06-2014-0131

Fratocchi L, Di Mauro C, Barbieri P et al (2014) When manufacturing moves back: Concepts and questions. J Purch Supply Manag 20:54-59. https://doi.org/10.1016/j.pursup.2014.01.004

Fratocchi L, Silva SCS (2018) Manufacturing back-shoring and direct brand creation in the footwear industry. In: Advances in Transdisciplinary Engineering. pp 461-466

Gray JV, Esenduran G, Rungtusanatham MJ, Skowronski K (2017) Why in the world did they reshore? Examining small to medium-sized manufacturer decisions. J Oper Manag 49-51:37-51. https:// doi.org/10.1016/j.jom.2017.01.001

Gylling M, Heikkilä J, Jussila K, Saarinen M (2015) Making decisions on offshore outsourcing and backshoring: A case study in the bicycle industry. Int J Prod Econ 162:92-100. https://doi. org/10.1016/j.ijpe.2015.01.006

Hogan J, Hogan R (2002) Leadership and sociopolitical intelligence. Mult. Intell. leadership. $75-88$

Hogan R (1994) Trouble at the Top: Causes and Consequences of Managerial Incompetence. Consult Psychol J 46:9-15. https:// doi.org/10.1037/1061-4087.46.1.9 
Johansson M, Olhager J (2018) Manufacturing relocation through offshoring and backshoring: the case of Sweden. J Manuf Technol Manag 29:637-657. https://doi.org/10.1108/JMTM-01-2017-0006

Joubioux C, Vanpoucke E (2016) Towards right-shoring: a framework for off-and re-shoring decision making. Oper Manag Res 9:117132. https://doi.org/10.1007/s12063-016-0115-y

Kahneman D, Tversky A (1984) Choices, values, and frames. Am Psychol. https://doi.org/10.1037/0003-066X.39.4.341

Kellerman B (2004) Bad leadership: What it is, how it happens, why it matters

Kinkel S (2014) Future and impact of backshoring-Some conclusions from 15 years of research on German practices. J Purch Supply Manag 20:63-65. https://doi.org/10.1016/j.pursup.2014.01.005

Kinkel S (2012) Trends in production relocation and backshoring activities: Changing patterns in the course of the global economic crisis. Int J Oper Prod Manag 32:696-720. https://doi. org/10.1108/01443571211230934

Kinkel S, Maloca S (2009) Drivers and antecedents of manufacturing offshoring and backshoring-A German perspective. J Purch Supply Manag 15:154-165. https://doi.org/10.1016/j.pursup. 2009.05.007

Larsen MM, Manning S, Pedersen T (2013) Uncovering the hidden costs of offshoring: The interplay of complexity, organizational design, and experience. Strateg Manag J 34:533-552. https://doi. org/10.1002/smj.2023

Fiona L, Peterson C, Tiedens LZ (2004) Mea culpa: Predicting stock prices from organizational attributions. Personal Soc Psychol Bull. https://doi.org/10.1177/0146167204266654

Leslie J, Velsor E Van (1996) A look at derailment today: North America and Europe

Lundberg CC, Thompson JD (1967) Organizations in Action. Adm Sci Q. https://doi.org/10.2307/2391555

Martínez-Mora C, Merino F (2014) Offshoring in the Spanish footwear industry: A return journey? J Purch Supply Manag 20:225-237. https://doi.org/10.1016/j.pursup.2014.07.001

McCall M, Lombardo M (1983) Off the track: Why and how successful executives get derailed.

Mintzberg H (1978) Patterns in Strategy Formation. Manage Sci. https:// doi.org/10.1287/mnsc.24.9.934

Nelson RR, Winter SG (1982) An Evolutionary Theory of Change

Nujen BB, Halse LL (2017) Global shift-back's: A strategy for reviving manufacturing competences. In: Breaking up the Global Value Chain. pp 245-267

Nujen BB, Halse LL, Damm R, Gammelsæter H (2018a) Managing reversed (global) outsourcing - the role of knowledge, technology and time. J Manuf Technol Manag 29:676-698. https://doi. org/10.1108/JMTM-02-2017-00232017-0023

Nujen BB, Mwesiumo DE, Solli-Sæther H et al (2018b) Backshoring readiness. J Glob Oper Strateg Sourc 12:172-195. https://doi. org/10.1108/JGOSS-05-2018-00202018-0020

Palmer M, Simmons G, de Kervenoael R (2010) Brilliant mistake! Int J Retail Distrib Manag, Essays on incidents of management mistakes and mea culpa. https://doi.org/10.1108/09590551011032072
Patton MQ (2002) Two Decades of Developments in Qualitative Inquiry: A Personal, Experiential Perspective. Qual Soc Work 1:261-283. https://doi.org/10.1177/1473325002001003636

Prahalad CK, Bettis RA (1986) The dominant logic: A new linkage between diversity and performance. Strateg Manag J. https://doi. org/10.1002/smj.4250070602

Saunders M, Lewis P, Thornhill A (2003) Research Methods for Business Students, Third edit. Pearson Education Limited

Silva SC, Meneses R, Radomska J (2018) A holistic perspective on the international market selection phenomenon. J East Eur Manag Stud 23(4):529-552

Silva SC, Silva MF (2012) Failure is a stepping stone for success. Int Rev Public Nonprofit Mark 9:153-179

Smart C, Vertinsky I (1977) Designs for crisis decision units. Adm Sci Q. https://doi.org/10.2307/2392406

Srai JS, Ané C (2016) Institutional and strategic operations perspectives on manufacturing reshoring. Int J Prod Res 54:7193-7211. https:// doi.org/10.1080/00207543.2016.1193247

Stentoft J, Olhager J, Heikkilä J, Thoms L (2016) Manufacturing backshoring: a systematic literature review. Oper Manag Res 9:53-61. https://doi.org/10.1007/s12063-016-0111-2

Van E, Leslie JB (1995) Why executives derail: perspectives across time and cultures. Acad Manag Perspect 9:62-72. https://doi. org/10.5465/ame.1995.9512032194

Verdu AJ, Gómez-Gras JM, Martínez-Mateo J (2012) Value creation through production offshore-inshore strategies in a footwear industry cluster: A coevolutionary perspective. Int Bus Rev 21:342-356. https://doi.org/10.1016/j.ibusrev.2011.04.001

Voss C, Johnson M, Godsell J (2016) Case research. In: Karlsson C (ed) Research Methods for Operations Management, 2nd Editio. Routledge, London, pp 165-197

Voss C, Tsikriktsis N, Frohlich M (2002) Case research in operations management. Int J Oper Prod Manag 22:195-219. https://doi. org/10.1108/01443570210414329

Wan L, Orzes G, Sartor M, et al (2019) Entry modes in reshoring strategies: An empirical analysis. J Purch Supply Manag 25

Weick KE (1995) Sensemaking in Organizations (Foundations for Organizational Science). Star 235

Wiesmann B, Snoei JR, Hilletofth P, Eriksson D (2017) Drivers and barriers to reshoring: a literature review on offshoring in reverse. Eur Bus Rev 29:15-42. https://doi.org/10.1108/ EBR-03-2016-0050

Yin RK (2003) Case study research: design and methods, 3rd edn. Sage publications, Thousand Oaks, CA

Publisher's Note Springer Nature remains neutral with regard to jurisdictional claims in published maps and institutional affiliations. 